ing through this opening-if we may call it an openingand if one or both of these nerves are impacted, naturally parall there will be pain until these nerves are, so to speak, tion of and therefore the pain will cease after the expiraomi a certain amount of time. I believe, from an anat. take standpoint, that if the surgeon or gynecologist would from the

$D_{H}$ the sutures, no pain need be experienced by the patient. tures. H. P. Newann, San Diego: The muscles and struchigh converge at the pubic spine. By making the incision Aroup one does not disturb any of these important structures. cular the external inguinal ring there are converging mus. ment fibers, and when these are injured any subsequent moveby the the body causes pain and distress. This is obvinted

cleurness, logic and knowledge. When they give advi'c, we presume that back of it are experience, carcful thought and good reason, though they may not think it necessary to impart all this to their humble followers

In hunting for reasons why hysterectomy is advocated as a cure for prolapse, I have failed to find the answer, except from Goffe. Carstens points to the absurdity of preserving a useless organ. Others leave it to be inferred that the question requires no answer because the proposition is self-evident, viz., if the uterus is removed it cannot again prolapse.

'The clearest explanation of why the uterus should be removed and how it may be done, so as to meet the conditions surrounding a complete prolapse, is given by Gofle. In an article read before the American Gynecological Society, May, 1910, on the relief of extreme cases of procidentia, cystocele, and rectocele, he says:

This, as I am sure you will all recognize, has been a most difficult condition to relieve, and while many of the best minds in our specialty have given much time and serious attention to it, no procedure has emanated from their hands that has given permanent or satisfactory results. As one of our numlier, after sitting at my elbow, two or three years ago, and witnessing two of my operations, remarked, "I have long folt that about all the problems in gynecology have been satisfactorily solved by us, except this one of cystocele and procidentia. I am convinced now that you have hit on the right principle and solved the problem."

Further on he says, "In cases which occur in women at or near the menopause, there is such a relaxation and complete lack of support in the tissue that the normal sustaining qualities of the tissues are hopelessly lost." Again, "All methods that have been previously resorted to, to retain the utcrus in these cases, have proved umavailing." Finally, "It is my custom, therefore, in all these cases to remove the uterus."

In aclition to Goffe's attitude it may easily be slown that the weight of authority in recent literature is in favor of hysterectomy. In view of these facts I wish to enter my feeble protest against the general acceptance of this judgment. A large number of eareful men consider that satisfactory results are obtained by preserving the nterus, and are firmly convinced that its romoval entails a distinct disadvantage. The question, then, is still an open one, and we are still at liberty to discuss which is the operation of choice in cases of severe prolapse.

\title{
PRELIMINARY CONSIDFMATIONS
}

Recurrence-The unjersal complaint of operators who have had much experience with treating genital prolapse is recurrence after operation. It is found, however, that in the great majority of cases, it is the cystocele alone that recurs. Dickinson calls attention to this point, and remarks that such results call for an orerhanling of our methods of operating.

Importance of the Cystocele.-To fasten the uterus so that it cannot again protrude is comparatively easy; witness Harris' operation of imbedding the uterus in the abdominal wall. But to prevent the bladder from again coming down is a very difficult problem. It appears to me that failure to recognize the relative importance of the cystocele as a complication of genital prolapse has obscured the true principles of operative treatment. Undue prominence has always been given the uterus. All measures have centered about this organ, while the support of the bladder has been overlooked or deemed a minor consideration. Practical experience shows that the order of importance shnuld 
be reversed. The problem becomes, then, "How can we prevent the recurrence of cystocele in operating on severe forms of procidentia?"

l'rolapse a Hernia.-A casual examination of a complete prolapse shows that it presents all the characteristics of a hernia. Uterus, bladder and rectum have pushed through the pelvic floor. It is quite evident that the opening through the levator ani is abnormally large. It needs no argument to show that restoration of the pelvic floor is necessary to any successful operation. 'l'his means, however, not an ordinary perineorrhaphy, but an actual exposure and direct union of the edges of the levator ani. 'The rectocele is sufficiently cared for by this repair, becnuse by the approximation of the edges of the levator the rectum is pushed back and held back.

Irernia of Bladder.-The cystocele (Fig. 1) complicating procidentia uteri is also a hernia, viz., of the bladder into the vagina. When we examine the bladder support we find that the base corresponds to a portion of the anterior vaginal wall. This structure (Fig. 2) consists practically of three layers - vaginal mucosa, bladder wall, and a thin layer of fascia between. Neither
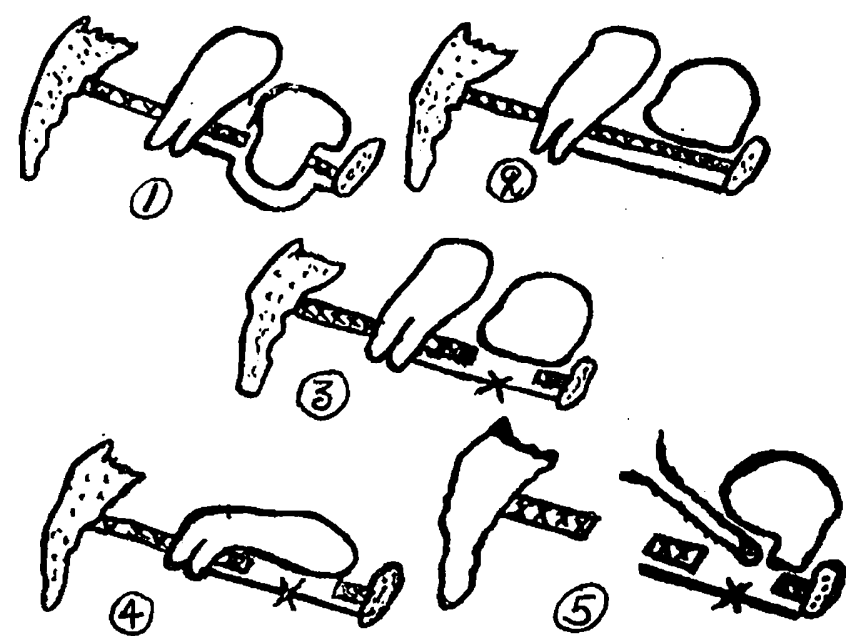

Fig. 1.-The cystocele complieating plocldentin uterl is also a helnit.

Flg. 2.-I'aralleisin of anterior vaginal wnll and base of bladaer. Fig. 3.- Bladder restored to place by a colporrhuply.

Fig. 4.-Dituwing uterus forwnid between bladder and varina. bladder and vagina after hysterectomy.

bladder wall nor vaginal wall is designed to act as a supporting structure because they easily stretch or distend. There remains, then, only the thin layer of fascia as the true support of the hase of the bladder. When once this fascia becomes overstretched or aplit and a severe cystocele occurs, it bccomes impossible to restore its full integrity.

\section{SIMPLE COIJPORRIAPHY INADEQUATE}

In the operation of anterior colporrhaphy, no operator pretends to identify the fascia and unite. it. At best, he makes a wide denudation, pushes the bladder back, takes up all the slack possible in the anterior wall, and unites the edges of the vaginal mucosa by rather deep sutures.

We have, then, as a result of an ordinary colporrhanhy (Fig. 3), the blaclder restored to place but supported only by a layer of vaginal mucosa. When we consider that the bladder is a "shifting water bag jounced when full and often overfull," as Dickinson expresses it; that it is constantly pressed on by weight of organs above, by the pressure of corsets, and the straining of constipation, it becomes plain that recurrence of a cystocele after an ordinary colporrhaphy is almost inevitable.
REENPORCEMTENT OF VAGINAL WALC NECESBARY

In order to prevent recurrence, something must be supplied to take the place of the injured fascia. In other words, in order to provide an efficient support the bladder, the anterior vaginal wall must be reenforced.

If we examine the various operations for prolapse. We find that tew of them make any mention of the cystoces problem. Philander Harris, for instance, proposes to bury the uterus within the abdominal wall. It is true, the uterus cannot again prolapse, but how about the cystocele? M. I. Harris proposes to dissect out the psoas parvus and attach it to the cervix, but leaves the cystocele to take care of itself. Iiclly's standard operation is nothing more than a colporrliaphy for the sup port of the bladder.

\section{METHODS OF' STRENGTHINITA 'TITE SUPPORT OF} 'THI: BLADDLR

There are two obvious and comparatively simple methods of supplying the necessary reenforcement:

1. The utcrus may be diawn forward and placed between the bladder and vagina (Fig. 4) or,

. After a hysterectom and broad ligaments may be drawn forward beneath the bladder and united so as to give the necessary support (Fig. 5).

The former method represents the old operation of interposition or vagino-fixation as elaborated by Dührsand techic has been illustrated beautifully by Watkins. The latter operation is due to Goffe.

How other surgeons provide for an adequate support of the bladder is not a matter of common knowledge. As far as I can see, the operation for prolapse in elder women and under ordinary circumstances is narrowach down to a choice between these two procedures. and recognizes the necessity of supporting the bladder ingry each provides an adequate means. It is not neces rinto give the technic of either operation. The basic prit ciples are clear and the operations are well known.

\section{WIIY RIMOVE THE UTERUS?}

Granting, then, that there is no special indication for hysterectomy, which should be the operation of choice?

As prescrvation of the uterus is more conservativc, hnce burden of argument f'or removal of the organ at tliem falls on those who favor liysterectomy. It is for the to demonstrate its superiority before advocating radical and more difficult procedure. But, on gener. principles, the choice may be made by comparing te tive results, simplicity and safety.

'The implication in Goffe's statement quoted above, that interposition of the uterus is not satisfactory, It disproved daily by the testimony of many operators. widely is liardly necessary to show that interposition is what and successfully practiced, but it may be mentioned 100 according to Watkins the Mayos have done a of these operations and report excellent results.

In interposition of the uterus a broad solid sup of is provided for the bladder without a large amounort cutting and sewing. The ligaments assist in the stelions and certainly are more secure in their normal reat to each to the uterus than when detached and sewed to other.

Hysterectomy with union of the ligaments is technically difficult. The support provided is chiefty with united round ligaments and these by comparison whesthe broad surface of the uterus form merely line on which to hang the bladder. 
With the water-bag lianging on the line the point of thion of the round ligaments is subjected to considerable attended When we remember that vaginal sections are netive by profuse bleeding, extensive opening of conpuration tissue spaces and imperfect asepsis and that supmon, ligament wust realize that risk of failure in getting the aments to unite is considerable.

\section{CONCLOSIONS}

lapse is recurrence of cystocele after operations for pro2. is very common.

2. Anterior colporrhaphy is not an efficient remedy. requiremerder to prevent recurrence the two prime wall and are reenforcement of the anterior vaginal 4. Re functional restoration of the levator ani.

easy, Reenforcement by interposition of the uterus is procedufe, conservative and altogether a satisfactory 5 . Une.

5. Unless specially indicated, lysterectomy for the distinct prolapse is unnecessary, complicated and entails Why disadvantages.

obtained then remove the uterus when good results are by preserving it?

\begin{abstract}
OF DISCLSSION
for the Phlaniber A. Harris, Paterson, N. J.: Operation $W_{e}$ shoure of cystocele has too often been unsatisfactory. of cystould also know that removal of the uterus for the cure procedure and partial descent of the uterus is a most unwise recur afe; inversion of the vagina and cystocele too often of the rer removal of the uterus. For the cure of inversion since, vagina following vaginal hysterectomy, I, a few years sisted in 'This in transfixing the vagina with the round lignments. cele and peration relieved or cured all of the patients with cysto. of the prolipse of the vagina. In advising against removal correct and for cystocele Dr. Somers has undonbtedly repeated ceed throuce in this relation. To what extent one may sue. know, through the operation described by Dr. Somers, I do not that its lery new measure must be well tried ont in order know the value may be determined. It will be interesting to never interter results of the operation which he advocntes. I cure of intencled that the operntion which I described for the onstrated prolapse of the uterus, and which Dr. Somers has demcystocele on the screen from one of my drawings, should cure cases; that although it did cure this condition in a number of "intramurat is, I performed my operation, which is termed lapse of the sequestration and fixation for the cure of pro. was either utrrus," and incidentally I found that cystocele
\end{abstract} $D_{R}$, ser relievel or cured in all of these cases.

Iterus. M. D. Crark, New Orleans: I always conserve the it serves curing these patients with prolapse and believe that valuable in splendidly as a plug for the liernin. It is especially know is in obliterating the hernia of the bladder, which we in these case of the most difficult phinses to handle successfully monthe cases. I had one of these interesting cases twelve the uterus, in which there was complete prolapse, not only of In thisus, but also of the anterior and posterior vaginal walls. further in I followed the so-called Watkins idea, going even of the uterunging the base of the broad ligaments in front round ligas on a level with the internal os; also suturing the strong gaments strongly across the fundus of the uterus. A the Wathingior colporraphy was built up in conjunction with the pations, but to my disappointment I lad a letter from Was eviclent's physician after four months, saying that there found at of a recurrence. When the patient returned, I protrude the examination that the cervix was beginning to vaginal from the vaginal orifice, as well as the posterior cured. It and I could only say that the cystocele had been cedure It was a problem for me to determine the best prolifting the follow, but I decided on opening the aldomen and inal wall, posterior cul-de-sac with the cervix up to the aldom. wall, where it was anchored firmily to the nuscles of the abdomen. This, so far, has cured the patient, and I think it was the best procedure to follow in this instance, from the fact that I would have had great dificulty in extricating the fundus of the nteris from benentl, the bladder, and furthermore, it would have removed that which gave the latter organ support. I have mever seren a case handled in a similar manner.

Dr. I. G. Bowsrs, Dayton, O.: Mutilation to correct a displacement of the nterus is not a good procedure. One thing which we overlook in the cure of cystocele is the long anterior wall. In this case if one demules and puts in sutures one corrects the size but does not change the length. My habit is to do as in ordinury hernia: make a long incision and raise the edge with knife and forceps, cutch the raised edge with dry gauze and strip the blalder awny from the nterus for nearly an inch above its normal attachinent to the uterus. One gets thus a hernial sac. A diamond-shaped piece is removed and stitched up in such a munner as to give a plus-shaped suture line. The lower stitch is so plucel that it catches the uterus under the bladder. Most of these cases require an amputation of the cervix. All require some suspension of the uterns. I use either the external Alexander or the Gilman operation.

Dr. Fraxk P. 'olprixa, San Franciseo: I helieve that in the restoration of the pelvic floor, any of the recognized operations are good and that in any repair temporary reliof is oltained. The test is made only by time. Patients come lack three to five years afterward for relaxed vaginal outlet and for cystocele. You will find that in eases in which the plastic result looked so well at the time of and following the operation, there has been a great relaxation when the levator ani museles have not been brought into apposition. Although bealing has been perfect, the anterior bladder wall has stretched. I think it is mainly in the large clinies that one can follow the cases. In the Cooper College Clinic we have a number of these cases. It is true that when the uterus has been removed patients are rid of the procidentia, but they come back with persistent cystocele, which is as troublesome as the original cause of the complaint-prolapse of the uterus. Were it possible to suspend the bladder as one can suspend the uterus in Kelly's ventrosuspension. it would be all right. But this being impossible, that by getting a wedge from below and by inverting the uterus and sewing it below the posterior bladder will one comes nearer to it than by any other operation.

Dr. H. O. WhIre, Chicago: From an nnatomic standpoint, I do not believe it is correct to say "pelvic hernia," for there is a great deal of difference between hernia and prolapse, A hernia is a protrusion of a viseus through an abnormal opening. The vaginal opening is not an abnormal opening. IVe have inguinal hernia where a viscus is protruding through an external or internal abdominal ring, but really there are no such things. It is when the viseus forms an opening that we call it a hernia. Hence, all these prolapses through the vaginal openings I would simply call prolapses and not hernins.

1). G. B. Somers, San Francisco: You will notice that I have been very careful not to discuss technic. The paper was simply a consideration of the brond question as to which is the better procedure-removal of the uterus or preservation of the uterus. I have tried to show that I favor preservation of the uterus, when possible, on the ground that it gives good and sufficient support. I do not wish it to be understood that I regard interposition us a perfect operation. Some operators lave failed with it. Those who do the operation may at times notice that the uterus lias a tendency to double on itself, throwing the cervix downwarl and forward. The fault here is technical. The trouble is that we have not paid sufficient attention to taking up the slack in the anterior vaginal wall in the neighborliood of the cervix. Again, all the points along the neck of the uterus as well as the fundus should be sutured to the anterior vaginal wall. I do not care to discuss teclinic further except to reply to the speaker who suggested a way of shortening the vagina. The anterior vaginal wall should not be shortened from before backward for such a procedure will result in a presentation of the cervix at the vaginal ontlet. One of the principles we must carry out is to have the fundus low and keep the cervix high. To shorten the vagina drags the cervix down. It appenrs to me, however, that if we can first determine what should be the operation of choice, then these points in technic are capable of solution later. 